\title{
Association between Depression and Dentition: A Study among Geriatric Patients in Kuala Langat, Malaysia
}

${ }^{1}$ Shivani Kohli, ${ }^{2}$ Christopher D Philip, ${ }^{3}$ Cassamally M Aadil, ${ }^{4}$ Aaron LW Vun, ${ }^{5}$ Mahenthiran Ramalingam

\section{ABSTRACT}

Aim: The aim of this study was to determine association between depression and dentition and others covariates among the elderly in Kuala Langat region, Malaysia.

Materials and methods: A cross-sectional study was conducted among elderly subjects aged 60 years and above. Geriatric depression scale (GDS) was used to classify the subjects into different grades of depression: 0 to 4 (no depression), 5 to 9 (mild depression), and 10 to 15 (moderateto-severe depression). Demographic data and details of the subjects' dentitions were collected using a self-administered questionnaire.

Results: There was a statistically significant association between dentition and depression, with $p=0.0000881$ where $p<0.05$. Difficulty in performing daily activity was also significantly associated with depression, with $p=0.0477$ where $p<0.05$. Participants who cannot chew well had higher percentage of depression compared with subjects who can chew well.

Conclusion: According to the results obtained, there was a statistically significant association between dentition and depression. Oral health awareness may help to reduce the severity of depression among the elderly.

Clinical significance: The importance of this study was to highlight that maintaining a proper dentition either natural or artificial may reduce the incidence of depression among the elderly; as loss of teeth is a vital risk factor, it can be prevented by use of dentures or other forms of prosthesis. On the other end of the spectrum, physiological consequences of depression may lead to decline in oral health as well.

Keywords: Age, Cross-sectional study, Depression, Older, Teeth.

How to cite this article: Kohli S, Philip CD, Aadil CM, Vun ALW, Ramalingam M. Association between Depression and Dentition: A Study among Geriatric Patients in Kuala Langat, Malaysia. World J Dent 2018;9(4):304-309.

\section{Source of support: Nil}

Conflict of interest: None

${ }^{1}$ Department of Prosthodontics, Faculty of Dentistry, MAHSA University, Selangor, Malaysia

${ }^{2-5}$ Faculty of Dentistry, MAHSA University, Selangor, Malaysia

Corresponding Author: Shivani Kohli, Department of Prosthodontics, Faculty of Dentistry, MAHSA University Selangor, Malaysia, e-mail: shivani@mahsa.edu.my

\section{INTRODUCTION}

Depression is common in old age. ${ }^{1}$ It is defined by the World Health Organization (WHO) as a common mental disorder, characterized by sadness, loss of interest in daily activity or pleasure, feelings of guilt or low self-worth, disturbed sleep or appetite, feelings of tiredness, and poor concentration. ${ }^{2}$ Depression is recognized as a globally serious health concern in modern countries. ${ }^{3,4}$

It is one of the leading causes in global diseases burden following after ischemic heart disease and known as one of the most common geriatric psychiatric disorders which can manifest as major depression or as minor depression characterized by a collection of depressive symptoms and is often difficult to diagnose. ${ }^{5-7}$ According to Global Burden of Disease profile (2010), major depression is one of the top three leading causes of disability in Malaysia. ${ }^{8}$ Studies have proven that geriatric depression is related with sociodemographic factors and present physical illnesses. ${ }^{9}$

Until now, a very few studies have been conducted on geriatric depression among the general communities in Malaysia. As the quality of life expectancy increases, the percentage of incidence of depression of the elderly may increase. ${ }^{10,11}$ If depression in elderly is left undiagnosed and untreated, it could result in reduced quality of later life and may cause worsening in health conditions, which eventually may lead to increase in morbidity and mortality. ${ }^{12,13}$

Dentition is important not only for chewing food, esthetics, and pronunciation, but is also vital in maintaining general health. Oral health-related quality of life can be compromised if diseases and disorders cause dental and craniofacial defects which can influence selfimage, self-esteem, and well-being. Oral limitations can affect a person to lose their appetite, limit their food consumption, restrict social communication, and deplete intimacy. ${ }^{10}$

Physical weakness and lack of motivation, as well as negative thought are associated with depression which may have a detrimental effect on oral hygiene habits and compliance with recommended treatment. ${ }^{14,15} \mathrm{~A}$ depressed patient frequently will drop interest for basic self-care activities. ${ }^{16}$ The relationship between poor dental health and depression has not been well understood. Even so, depression was found to have involved in periodontal 
destruction, poorly perceived oral health, and oral health concerns. ${ }^{17}$ In Malaysia, this is a pioneer study to evaluate the relationship between dentition and depression. The aim of this study was to evaluate the association between dentition and covariates in relation to depression among the elderly.

\section{MATERIALS AND METHODS}

\section{Study Population}

This cross-sectional study was conducted between September 2015 and February 2016, involving the geriatric population aged 60 years and above residing within the Kuala Langat region as well as patients who visited dental clinics of MAHSA University, Bandar Saujana Putra (Kuala Langat region, Malaysia) for treatment. The selected study area is a populated and well-developed area within the state of Selangor, with an estimated geriatric population of 220,214 (aged 60 years and above).

\section{Sample Size Estimation}

Estimation of sample size was done using the sample size formula for finite population:

$$
\frac{N t^{2} p q}{d^{2}(N-1)+t^{2} p q}
$$

Here, the confidence interval (CI) was taken as $95 \%$.

$\mathrm{t}$ is the normal deviation corresponding to the required $\mathrm{CI}$.

Here, it was 1.96 for $95 \%$ CI.

$\mathrm{p}$ is $6.3 \%$ prevalence rate of depression in elderly in Malaysia $=0.0063$

$\mathrm{q}$ is $(1-\mathrm{p})$. Here, it is $(1-0.063)=0.937$

$\mathrm{d}$ is the allowable error; $5 \%=0.05$.

$\mathrm{N}$ is the total geriatric population ( $\geq 60$ years) within Kuala Langat region $=220,241$ participants.

Geriatric population aged 60 and above within the Kuala Langat region was estimated by totaling the number of residents (60 years and above) in all districts in the Kuala Langat region (which consisted of Bandar Saujana Putra, Banting, Dusun Durian estate, Jenjarom, Sungai Manggis, Morib and Kanchong); it was obtained from the population distribution statistics of the year 2010 on the official portal of Department of Statistics Malaysia. ${ }^{18}$ The prevalence rate of depression among the geriatric population in Malaysia was set as 6.3\%, based on a previous study conducted in the year $2005 .{ }^{19}$ The sample size needed was estimated to be around 90.7 according to the above-mentioned formula.

This study was conducted by using snowballing sampling method, where respondents were obtained by word of mouth and door-to-door visits by an individual oral categorized interview. Additionally, observations were made using a direct and spontaneous technique as a supplementary method. Informed consent was obtained from the participants before the commencement of the study. Subjects with age equal to or more than 60 years of both sexes, and from any racial background in the Kuala Langat region, those who are able to self-report, understand verbal communication, and can follow instructions were included in the study. Participants who were unable to provide consent (either written or verbal), which could be due to terminal illness and severe articulation or auditory impairment were excluded from the study.

\section{Dental Variables}

A self-administered questionnaire was used to assess dentition and chewing ability among the participants, where the interviewer observed and categorized subjects' dentition as having 20 teeth or more, 19 teeth or fewer with dentures, 19 teeth or fewer without dentures, or absence of teeth. While the participants' chewing ability was ascertained by asking questions, such as "Are you able to chew everything?", "Are you able to chew most of the food?", "Cannot chew very well", and "Can't chew at all?"

\section{Covariables}

There are numerous screening instruments available to detect depression among geriatric subjects. One of the most widely used instruments is the GDS (Table 1). The GDS had a specificity of $89 \%$ and a sensitivity of $92 \% .{ }^{20,21}$ Hence, to evaluate depression, the Geriatric Depression Scale-15 (GDS-15) was administered with simple 15 questions with

Table 1: Geriatric depression scale (GDS-15)

Circle the most appropriate answer for how you have felt over the past week:

1. Are you basically satisfied with your life? YES/NO

2. Have you dropped many of your activities and interests? YES/NO

3. Do you feel that your life is empty? YES/NO

4. Do you often get bored? YES/NO

5. Are you in good spirits most of the time? YES/NO

6. Are you afraid that something bad is going to happen to you? YES/NO

7. Do you feel happy most of the time? YES/NO

8. Do you often feel helpless? YES/NO

9. Do you prefer to stay at home, rather than going out and doing new things? YES/NO

10. Do you feel you have more problems with memory than most? YES/NO

11. Do you think it is wonderful to be alive now? YES/NO

12. Do you feel pretty worthless the way you are now? YES/NO

13. Do you feel full of energy? YES/NO

14. Do you feel that your situation is hopeless? YES/NO

15. Do you think that most people are better off than you are? YES/NO 
yes or no format. The participants were then divided into three groups based on their level of depression, where they were classified into three groups: 0 to 4 (no), 5 to 9 (mild), and 10 to 15 (moderate-to-severe). ${ }^{22,23}$ Sociodemographic data, such as sex, age, and income were obtained using a self-administered questionnaire. Ethical clearance was obtained prior to commencement of the study. Data were analyzed using Pearson's chi-square test while Fisher's exact test was employed when variables for the Pearson's chi-square test had an expected count of less than five. All the variables were described in numbers and percentages. Univariate analysis was done to evaluate the association of all variables with depression.

\section{RESULTS}

Out of the 246 participants encountered during the course of the study, 142 were excluded from the study, as they were unwilling to participate, noncompliant, and did not conform to the criteria of the study; $29.8 \%$ of the 104 participants were suffering from some form of depression. Descriptive data of dentition and covariate in relation to depression are shown in Table 2.

The association of dentition and covariates with depression are shown in Table 3 . The results of the present study does show that there was a statistically significant association between dentition and depression, with $\mathrm{p}=0.0000891$, odds ratio (OR) $0.18,95 \%$ CI 0.0748 to 0.4332 ; where $\mathrm{p}<0.05$. Difficulty in performing daily activity was also significantly associated with depression, with $\mathrm{p}=0.0477$, OR 2.6617, 95\% CI 1.0519 to 6.7349 , where $\mathrm{p}<0.05$.

The prevalence rates are shown in Table 4. According to the present study, the prevalence rate of depression for those who had 19 teeth or less in total with or without denture was higher than those who had 20 teeth or more

Table 2: Descriptive data of dentition and covariates in relation to depression

\begin{tabular}{|c|c|c|c|c|}
\hline \multirow[b]{2}{*}{ Master chart } & \multirow[b]{2}{*}{ Total } & \multicolumn{3}{|c|}{ Depression (GDS) } \\
\hline & & No & Mild & Moderate-to-severe \\
\hline \multicolumn{5}{|l|}{ Dentition } \\
\hline$\geq 20$ teeth & 25 & $20(80)$ & $4(16)$ & $1(4)$ \\
\hline$\leq 19$ teeth with dentures & 33 & $27(81.8)$ & $3(9.1)$ & $3(9.1)$ \\
\hline$\leq 19$ teeth without dentures & 40 & $24(60)$ & $12(30)$ & $4(10)$ \\
\hline Missing & 6 & $2(33.3)$ & $2(33.3)$ & $2(33.3)$ \\
\hline \multicolumn{5}{|l|}{ Chewing ability } \\
\hline Can chew anything & 39 & $32(82.1)$ & $5(12.8)$ & $2(5.1)$ \\
\hline Can chew most foods & 36 & $24(66.7)$ & $8(22.2)$ & $4(11.1)$ \\
\hline Cannot chew very well & 27 & 17 (62.9) & $7(25.9)$ & $3(11.1)$ \\
\hline Can't chew at all & 2 & 0 & $1(0.5)$ & $1(0.5)$ \\
\hline \multicolumn{5}{|l|}{ Age (years) } \\
\hline $60-64$ & 25 & $16(64)$ & $6(24)$ & $3(12)$ \\
\hline $65-69$ & 30 & $24(80)$ & $4(13.3)$ & $2(6.7)$ \\
\hline $70-74$ & 11 & $11(100)$ & 0 & 0 \\
\hline$\geq 75$ & 38 & $22(57.9)$ & $11(28.9)$ & $5(13.2)$ \\
\hline \multicolumn{5}{|l|}{ Sex } \\
\hline Male & 45 & $33(73.3)$ & $8(17.7)$ & $4(8.9)$ \\
\hline Female & 59 & $40(67.8)$ & $13(22)$ & $6(10.2)$ \\
\hline \multicolumn{5}{|c|}{ Difficulty in performing daily activities } \\
\hline Yes & 26 & $14(53.8)$ & $8(30.8)$ & $4(15.4)$ \\
\hline No & 78 & $59(75.6)$ & $13(16.7)$ & $6(7.7)$ \\
\hline \multicolumn{5}{|l|}{ Use of sedatives } \\
\hline Yes & 68 & $49(72.1)$ & $12(17.6)$ & $7(10.3)$ \\
\hline No & 36 & $24(66.7)$ & $9(25)$ & $3(8.33)$ \\
\hline \multicolumn{5}{|l|}{ Self-rated health } \\
\hline Excellent & 8 & $8(100)$ & 0 & 0 \\
\hline Good & 60 & $44(73.3)$ & $12(20.0)$ & $4(6.7)$ \\
\hline Fair & 35 & $20(57.1)$ & $9(25.7)$ & $6(17.1)$ \\
\hline Poor & 1 & $1(100)$ & 0 & 0 \\
\hline \multicolumn{5}{|l|}{ Household income (RM) } \\
\hline$<500$ & 88 & $60(68.2)$ & $21(23.9)$ & $7(7.9)$ \\
\hline $500-999$ & 4 & $3(75)$ & 0 & $1(25)$ \\
\hline 1000-1999 & 4 & $4(100)$ & 0 & 0 \\
\hline$>2000$ & 8 & $6(75)$ & 0 & $2(25)$ \\
\hline
\end{tabular}


Association between Depression and Dentition among Geriatric Patients

\begin{tabular}{|c|c|c|c|c|c|c|}
\hline \multirow[b]{2}{*}{ Covariates } & \multirow[b]{2}{*}{ Total } & \multicolumn{2}{|c|}{ Depression (GDS) } & \multirow[b]{2}{*}{$p$-value } & \multirow[b]{2}{*}{ OR } & \multirow[b]{2}{*}{$95 \% \mathrm{Cl}$} \\
\hline & & No & Mild-to-severe & & & \\
\hline \multicolumn{7}{|l|}{ Dentition } \\
\hline 20 teeth or more with/without denture & 58 & 47 & 11 & 0.0000881 & 0.18 & $0.0748-0.4332$ \\
\hline 19 teeth or less with/without denture & 46 & 26 & 20 & & & \\
\hline \multicolumn{7}{|l|}{ Age (years) } \\
\hline 70 and above & 49 & 33 & 16 & 0.668 & 1.293 & $0.5572-3.0004$ \\
\hline 60 to 69 & 55 & 40 & 15 & & & \\
\hline \multicolumn{7}{|l|}{ Chewing ability } \\
\hline Can chew most foods & 75 & 56 & 19 & 0.151 & 0.4807 & $0.1947-1.1868$ \\
\hline Can not chew & 29 & 17 & 12 & & & \\
\hline \multicolumn{7}{|l|}{ Sex } \\
\hline Male & 45 & 33 & 12 & 0.666 & 0.7656 & $0.3249-1.804$ \\
\hline Female & 59 & 40 & 19 & & & \\
\hline \multicolumn{7}{|l|}{ Difficulty in performing daily activity } \\
\hline Yes & 26 & 14 & 12 & 0.0477 & 2.6617 & $1.0519-6.7349$ \\
\hline No & 78 & 59 & 19 & & & \\
\hline \multicolumn{7}{|l|}{ Use of sedatives } \\
\hline Yes & 68 & 50 & 18 & 0.5001 & 0.72 & $0.2993-1.732$ \\
\hline No & 36 & 24 & 12 & & & \\
\hline \multicolumn{7}{|l|}{ Self-rated health } \\
\hline Good & 68 & 51 & 17 & 0.1172 & 0.4667 & $0.1974-1.1033$ \\
\hline Poor & 36 & 21 & 15 & & & \\
\hline \multicolumn{7}{|l|}{ Household income $(R M)^{*}$} \\
\hline 500 or less & 88 & 61 & 27 & 0.3882 & 1.918 & $0.5049-7.286$ \\
\hline 501 or more & 16 & 13 & 3 & & & \\
\hline
\end{tabular}

${ }^{*}$ Calculated using Fisher's exact test

Table 4: Prevalence of depression according to dentition and covariates

\begin{tabular}{|c|c|c|c|c|}
\hline Covariates & Total & Depression & $\begin{array}{l}\text { No } \\
\text { depression }\end{array}$ & $\begin{array}{l}\text { Prevalence } \\
(\%)\end{array}$ \\
\hline \multicolumn{5}{|l|}{ Dentition } \\
\hline $\begin{array}{l}20 \text { teeth or more } \\
\text { with/without } \\
\text { denture }\end{array}$ & 59 & 12 & 47 & 20.3 \\
\hline $\begin{array}{l}19 \text { teeth or less } \\
\text { with/without } \\
\text { denture }\end{array}$ & 45 & 19 & 26 & 42.2 \\
\hline \multicolumn{5}{|l|}{ Age (years) } \\
\hline 70 and above & 49 & 16 & 33 & 32.7 \\
\hline 60 to 69 & 55 & 15 & 40 & 27.2 \\
\hline \multicolumn{5}{|l|}{ Chewing ability } \\
\hline $\begin{array}{l}\text { Can chew most } \\
\text { foods }\end{array}$ & 75 & 16 & 59 & 21.3 \\
\hline Can't chew & 29 & 12 & 17 & 41.4 \\
\hline \multicolumn{5}{|l|}{ Sex } \\
\hline Male & 45 & 12 & 33 & 26.7 \\
\hline Female & 59 & 19 & 40 & 32.2 \\
\hline
\end{tabular}

with or without denture (42.2:20.3\%). About $32.7 \%$ of the participants aged 70 years and above were found having depression. Participants who cannot chew well had high percentage of depression (41.4\%) and females were more prone to suffer from depression with a rate of $32.2 \%$ compared with males.

\section{DISCUSSION}

This was a first study done among the Malaysian elderly population to evaluate the effect of dentition on depression. The present study show that there was an association between dentition and depression, as the subject with 19 or less teeth (including both natural and artificial) had a significantly higher rate of depression as compared with those with 20 teeth or more; $42.2 \%$ of geriatric patients with 19 teeth or less with/without denture were having depression, compared with $20.3 \%$ of geriatric patients with 20 teeth or more with/without denture. These findings were compatible with a cross-sectional study conducted among the Nigerian population where subjects with tooth loss showed higher levels of depression. ${ }^{24}$ These results suggest that loss of dentition may lead to depression.

There are several pathways in which dentition and depression can be related. Depression is associated with decreased metabolism of serotonin, which then tends to increase the consumption of carbohydrates, establish 
conditions favorable for the growth of aciduric bacteria that leads to the development and progression of dental caries and compromised dental status. ${ }^{16}$ On the contrary, tooth loss has both psychological and social impacts on the individual. Changes in appearance and speech, due to tooth loss can cause decrease in self-confidence of the patient. Coupled with this, the embarrassment of wearing dentures will have emotional effects leading to depression. $^{25}$

According to the present study, prevalence of depression among elderly was $29.8 \%$. This was low compared with the previous study by Teh and Hasanah, ${ }^{26}$ where the prevalence of depression was $36.6 \%$. According to $\mathrm{WHO}^{27}$ the overall prevalence rate of depression was between 10 and $20 \%$ among the geriatrics which differs subject to cultural situations. ${ }^{28}$ The prevalence of screeningbased depression using GDS-15 in other countries varied from $33.8 \%$ in Indonesia, to $30.3 \%$ in Japan and $17.2 \%$ in Vietnam. ${ }^{29}$

The results showed that those with compromised chewing had an incidence of depression which was in accordance with a finding obtained from a previous study among Japanese population which confirmed the existence of an association between low chewing ability and presence of depressive symptoms. ${ }^{30}$ Where there is loss of tooth, it will lead to a decrease in the chewing ability, which in turn will lead to a higher rate of depression. This was in agreement with the findings in another study where depression in adulthood was associated with self-reported chewing difficulties at an older age. ${ }^{31}$ On the contrary, a retrospective cohort study among the Chinese population showed that depression may negatively impact oral health and chewing ability through different pathways. ${ }^{32}$

In the present study, sex was not a risk factor for depression, as there was no association seen between sex and depression. However, there was a higher incidence of depression seen among women (32.2\%) as compared with males, which was similar to a study conducted by Wada et al. ${ }^{33}$ Household income was a risk factor for depression, which was in accordance with Koster et $\mathrm{al}^{34}$ who reported that people with low income had more depressive symptoms.

\section{CONCLUSION}

According to the results achieved from the present study, there was a statistically significant association between dentition and depression. Government and community dental care programs should try to work together as a team to raise oral health awareness which may help reduce the severity of depression among the elderly.

\section{ACKNOWLEDGMENT}

Authors would like to acknowledge Mr. Mohammad Zaki Noor, Faculty of dentistry, MAHSA University for the statistical analysis.

\section{REFERENCES}

1. IHME. Global burden of disease study 2010. Seattle (WA): IHME; 2010. [cited 2013 Jun 20]. Available from: http://ghdx. healthmetricsandevaluation.org/global-burden-diseasestudy-2010-gbd-2010-data-downloads.

2. World Health Organization. Mental health: depression: definition. Europe: World Health Organization; 2013. [cited 2013 Apr 26]. Available from: http://www.euro.who.int/en/ what-we-do/health.

3. Burke MM, Laramie JA. Primary care of the older adult: a multidisciplinary approach. 1st ed.St. Louis (MO): Mosby Inc; 2000.

4. Murray CJ, Lopez AD. Global mortality, disability, and the contribution of risk factors: global burden of disease study. Lancet 1997 May;349(9063):1436-1442.

5. O'Neil A, Berk M, Venugopal K, Jacka FN. The Association between poor dental health and depression: findings from a large-scale, population-based study (the NHANES study). Gen Hosp Psychiatry 2014 May-Jun;36(3):266-270.

6. Taqui AM, Itrat A, Qidwai W, Qadri Z. Depression in the elderly: does family system play a role? A cross-sectional study. BMC Psychiatry 2007 Oct;7:57.

7. Susman JL, Crabtree BF, Essink G. Depression in rural family practice. Easy to recognise, difficult to diagnose. Arch Fam Med 1995 May;4(5):427-431.

8. IHME. Global burden of disease. Malaysia: Institute of Health Metrics and Evaluation (IHME); 2010.

9. Verma RK, Min TU, Chakravarthy S, Barua A, Kar N. Sociodemographic correlates of unipolar major depression among the Chinese elderly in Klang valley, Malaysia: an epidemiological study. Sci World J 2014 Dec;2014:812712.

10. Evans CA, Kleinman DV, Maas WR, Slavkin HC, Wilentz JS, Price R, Fogelman M Part three: what is the relationship between oral health and general health and well-being? Chap.6: effects on well-being and quality of life. Rockville (MD): Department of Health and Human Services, National Institutes of Health, National Institute of Dental and Craniofacial Research; 2000.

11. Blanchard MR, Waterraus A, Mann AH. The nature of depression among older people in inner London and the contact with primary care. Br J Psychiatry 1994 Mar;164(3):396-402.

12. VanDerPol CA, Setter SM, Hunter KA, Pamintuan H. Depression in community dwelling elders. Postgrad Med 1998 Mar;103(3):165-167.

13. Mitchell AJ, Subramaniam H. Prognosis of depression in old age compared to middle age: a systematic review of comparative studies. Am J Psychiatry 2005 Sep;162(9):1588-1601.

14. Ohayon MM, Schatzberg AF. Using chronic pain to predict depressive morbidity in the general population. Arch Gen Psychiatry 2003 Jan;60(1):39-47.

15. Penninx BW, Deeg DJ, van Eijk JT, Beekman AT, Gurainik JM. Changes in depression and physical decline in older adults: a longitudinal perspective. J Affect Disord 2000 Dec;61(1-2):1-12.

16. Anttila SS, Knuuttila ML, Sakki TK. Relationship of depressive symptoms to edentulousness, dental health, and dental health behavior. Acta Odontol Scand 2001 Dec;59(6):406-412. 
17. Settineri S, Mallamace D, Muscatello MR, Zoccali R, Mento C. Dental anxiety, psychiatry and dental treatment: how are they linked? Open J Psychiatry 2013 Feb;3:168-172.

18. Department of Statistics Malaysia. Population and distribution by local authority areas and Mukims. Malaysia: Department of Statistics; 2012. Available from: http://www.statistics.gov.my/ portal/index.php?option=com_content\&id=1353\&lang=en.

19. Sherina MS, Rampal L, Aini M, Norhidayati MH. The prevalence of depression among elderly in an urban area of Selangor, Malaysia. Int Med J 2005 Jan;4(2):57-63.

20. Koenig HG, Meador KG, Cohen HJ, Blazer DG. Self-rated depression scales and screening for major depression in the older hospitalized patient. J Am Geriatr Soc 1998 Aug;36(8):699-706.

21. Yesavage JA, Brink TL, Rose TL, Lum O, Huang V, Adey M, Leirer VO. Development and validation of a geriatric depression rating scale: a preliminary report. J Psychiatr Res 1983;17(1):37-49.

22. Sheikh JI, Yesavage JA. Geriatric Depression Scale (GDS): recent evidence and development of a shorter version. Clin Gerontol 1986 Jun;5(1/2):165-173.

23. Harvath TA, McKenzie G. Depression in older adults. In: Boltz M, Capezuti E, Fulmer TT, Zwicker D, O'Meara A, editors. Evidence based geriatric nursing protocols for best practice. 4th ed. New York: Springer Publishing Company, LLC; 2012. pp. 135-162.

24. Okoje VN, Dosumu OO, Alonge TO, Onyeaso C. Tooth loss: are the patients prepared? Niger J Clin Pract 2012 AprJun;15(2):172-175.

25. Friedlander AH, Mahler ME. Major depressive disorder. Psycho-pathology, medical management and dental implications. J Am Dent Assoc 2001 May;132(5):629-638.

26. Teh EE, Hasanah CI. Validation of Malay version of geriatric depression scale among elderly inpatients. Malaysia: Journal of School of Medical Sciences, Universiti Sains Malaysia; 2004. [cited 2007 May 3]. Available from: http://www.priory.com/ psych/MalayGDS.htm.

27. World Health Report. Mental health: new understanding new hope. Geneva: World Health Organization; 2001. [cited 2013 May 3]. Available from: http://www.who.int/whr/2001/en/ whr01_en.pdf.

28. Wig NN. World health day 2001. Indian J Psychiatry 2001 Jan-Mar;43(1):1-4.

29. Wada T, Ishine M, Sakagami T, Kita T, Okumiya K, Mizuno K, Rambo TA, Matsubayashi K. Depression, activities of daily living, and quality of life of community-dwelling elderly in three Asian countries: Indonesia, Vietnam and Japan. ArchGerontol Geriatr 2005 Nov-Dec;41(3):271-280.

30. Kimura $Y$, Ogawa H, Yoshihara A, Yamaga T, Takiguchi $T$, Wada T, Sakamoto R, Ishimoto Y, Fukutomi E, Chen W, et al. Evaluation of chewing ability and its relationship with activities of daily living, depression, cognitive status and food intake in the community-dwelling elderly. Geriatr Gerontol Int 2013 Jul;13(3):718-725.

31. Aljameel AH, Watt RG, Brunner EJ, Tsakos G. Earlier depression and later-life self-reported chewing difficulties: results from the Whitehall II study. J Oral Rehabil 2015 Feb;42(2):98104.

32. Liao CH, Chang CS, Chang SN, Lane HY, Lyu SY, Morisky DE, Sung FC. The risk of temporomandibular disorder in patients with depression: a population-based cohort study. Community Dent Oral Epidemiol 2011 Dec;39(6):525-531.

33. Wada T, Ishine M, Kita T, Fujisawa M, Matsubayashi K. Depression screening of elderly community-dwelling Japanese. J Am Geriatr Soc 2003 Sep;51(9):1328-1329.

34. Koster A, Bosma H, Kempen GM, Penninx BW, Beekman AT, Deeg DJ, van Eijk JT. Socioeconomic differences in incident depression in older adults: the role of psychosocial factors, physical health status, and behavioral factors. J Psychosom Res 2006 Nov;61(5):619-627. 